\title{
Government initiatives
}

\section{The impacts of Chinese Nian culture on air pollution}

\author{
Chao Ye ${ }^{a}$, Ruishan Chen ${ }^{b}{ }^{*}$, Mingxing Chen ${ }^{c}$ \\ a College of Geographic Sciences, Nanjing Normal University, Nanjing 210023, China \\ b School of Public Administration, Hohai University, Nanjing 210098, China \\ ${ }^{c}$ Institute of Geographic Sciences and Natural Resources Research, CAS, Beijing 100101, China
}

\section{A R T I C L E I N F O}

\section{Article history:}

Received 26 December 2013

Received in revised form

23 January 2015

Accepted 19 April 2015

Available online 13 May 2015

\section{Keywords:}

Air pollution

Nian culture

PM2.5

China

\begin{abstract}
A B S T R A C T
Air pollution in China has attracted world attention again since the winter of 2012. Besides considering the normal level of air pollution, it is interesting and important to choose and analyze periods of extremely high levels. These extremes are not only important because high values of PM2.5 have more severe impacts, but also to help us to effectively understand the causes of air pollution. Energy consumption, driven by the burning of fossil fuels, and motor vehicle emissions are regarded as two main primary causes of air pollution. However, culture is a less-obvious factor affecting air pollution, which is often overlooked by researchers. Culture plays an important role in many environmental problems. This study investigates why and how "Nian" culture leads to increased air pollution during Chinese New Year. Air pollution during Chinese Lunar New Year is more severe than other times of the year. Although the relationship between the lighting of fireworks and air pollution is of wide concern, the cultural factors behind it are not fully recognized, which hinders the understanding and solving of the problem. It is an important step for Chinese people to reduce the lighting of firecrackers, believed to drive away monsters. Four solutions are proposed to deal with the severe air pollution problem during Chinese New Year.

(c) 2015 Elsevier Ltd. All rights reserved.
\end{abstract}

\section{Introduction}

Air pollution in China has become a global problem (Melamed et al., 2013). In the winter of 2012, air pollution in China was so severe that one-third of the Chinese territory was covered by fog and haze, and the continuously hazy weather in most big cities lasted for more than 30 days (Wang, 2013). The pollution had severe impacts, not only affecting tourism, transportation, and industrial development, but also human health. Many people suffered from a severe cough, especially in Beijing, where it became known as the "Beijing Cough".

Causes and effects of pollution vary with temporal and spatial scales. In order to understand better the process leading to air pollution, it is important that examine the typical temporal-spatial cases involved in extremely high levels of PM2.5, or particulate matter, air pollution. Particulate matter with a diameter of less than $2.5 \mu \mathrm{m}$ is small enough to directly enter the lungs and even the blood stream (Marshall, 2013). The concentration of PM2.5 is routinely used to describe air quality. The U.S. Environmental

\footnotetext{
* Corresponding author.

E-mail addresses: yeover@163.com (C. Ye), chenrsh04@gmail.com (R. Chen), chenmx@igsnrr.ac.cn (M. Chen).
}

Protection Agency (EPA) recognizes that it is unhealthy for sensitive individuals when concentrations of PM2.5 exceed $40.5 \mathrm{ug} / \mathrm{m}^{3}$, and unhealthy for the general population when the average concentration is above $65.5 \mathrm{ug} / \mathrm{m}^{3}$ for $24 \mathrm{~h}$. However, the PM2.5 concentrations are higher than the unhealthy level during most of the year in many of China's coastal cities (van Donkelaar et al., 2010). Levels of PM2.5 are very high during June each year in eastern cities of China, such as Nanjing, due to crop straw burning in surrounding rural areas (Hang and Chen, 2000; Yin et al., 2011; Zhu et al., 2010). The periods and locations facing extremely high PM2.5 pollution levels should be given greater emphasis in pollution research and control.

Culture plays an important role in many environmental issues (Milton, 2013). The relationship between cultural practices, sustainable development, and public participation is an issue to be explored (Jamison, 2001). Many scholars focus on environmental issues from the physical science perspective, but ignore social sciences and humanities. For example, Huang et al. (2012) analyzed air pollution during the agricultural harvest season in Eastern China, and pointed out that crop straw burning contributed significantly to fine particle pollution. However, the authors neglected to address the cultural causes of the pollution. The agriculture-related burnings are a long-term custom in countries like China and India. 
The farmers of these countries believe that nutrients will return to soil following burning.

As a hidden factor contributing to air pollution, culture is underestimated by scientists and governments, as in the above example. As far as the heavily polluted period is concerned, Chinese New Year is special because it is the most important festival for Chinese people. There is no doubt that Chinese New Year is a big cultural event, but unfortunately, the PM2.5 pollution levels during this period are higher than the other times, partly caused by the lighting of fireworks, and burning of incense, "ghost money", and other materials (Jun et al., 2007; Xu et al., 2006). However, it is unclear how and to what extent the Chinese Nian culture causes or exacerbates the pollution problems. Research on social movements, aimed at changing the traditional culture, have been insufficient. Therefore, this study illustrates how Chinese Nian culture triggers heavy pollution levels, and proposes some innovative solutions to deal with it.

\subsection{Chinese Nian culture and its impacts on air pollution}

As one of the most "complex, influential, and elusive" words in the English language, culture has many meanings (Williams, 1981; Gregory et al., 2009). Culture is both a 'total way of life' and a set of products reflecting human feelings (Mitchell, 2000). Although the concepts of culture are so varied and it is very difficult to define, the core meaning of culture is value or attitude (Crang, 1998). It is the different values or attitudes toward life that produce the various national and local cultures. Value can change, and so, culture is not unchangeable, but the speed and extent of cultural changes vary from one culture to another. On a temporal scale, culture can be classified into two types: traditional, such as Confucianism and Hellenism, and popular culture, pop songs, and films. Generally speaking, pop culture more easily changes or becomes outdated, but traditional culture consists of a value system developed over a long period, that it is very difficult to change over a short time period. The Chinese Nian culture is an example of traditional culture or customs, reflecting Chinese values.

The Chinese New Year (also known as the Lunar New Year) is termed "Nian" in Chinese. It is the most important holiday in China, as with Christmas in Europe and North America. The Chinese Nian generally starts one day before the Lunar New Year, and ends on the $15^{\text {th }}$ day. Among the 16 days of Chinese New Year, the first day, generally referred to as Chinese New Year's Eve, is the most important. The third or fifth, and the fifteenth are also significant days during the New Year period. Chinese New Year's eve, the night before the first day of Chinese New Year, is similar to Christmas Eve in Western Culture. All family members typically join together to celebrate Chinese New Year's Eve. The first day of Chinese New Year is the day a New Year starts, according to the lunar calendar. The third or fifth day of Chinese New Year is celebrated in different regions of China, with different themes. On the fifteenth day of Chinese New Year, called Chinese Lantern Festival, the end of Chinese New Year is celebrated.

Chinese New Year is a traditional custom that has existed for nearly 2000 years. In Chinese legends, "Nian" is a fierce monster that lives in the deep sea and comes appears on Chinese New Year's Eve to kill people and livestock. Continuous noises and fires must be created in order to drive this monster away (Ye et al., 2014). After their invention, their lighting of firecrackers gradually became a fixed part of the holiday custom. Nearly every Chinese household celebrates the New Year with fireworks and firecrackers. This creates a heavy environmental burden in Chinese cities. For example, Beijing produced 1586 tons of firework and firecracker trash from New Year's Eve until 9 am on the first day of the Chinese New Year in 2013 and required 93 thousand workers to clear up. The weights of trash in 2011 and 2012 were 2680 and 1741 tons, respectively (Rao, 2013). The PM2.5 concentration at Chegongzhuang air monitoring station was $1593 \mathrm{ug} / \mathrm{m}^{3}$ at one o'clock in the morning of the 2012 Chinese New Year's eve (Li, 2012), many times higher than the daily average limit of $75 \mu \mathrm{g} / \mathrm{m}^{3}$ set in China. Beijing produced 5505 tons of trash from fireworks and firecrackers from New Year's Eve until 6 am on the seventh day of Chinese New Year in 2013. More than 240 thousand sanitation workers were involved in the clean up (Huang, 2013). Although fireworks and firecrackers are a part of celebrations in other countries on New Year's day (Drewnick et al., 2006; Vecchi et al., 2008), their use is more extensive in China. The impacts of burning fireworks and firecrackers on air pollution during Chinese New Year has already aroused wide concerns (Shi et al., 2011; Wang et al., 2007; Yu et al., 2013; Zhang et al., 2010; Cheng et al., 2014; Li et al., 2009).

Chinese New Year is also a holiday to worship the gods and ancestors. Burning incense is very popular in Chinese temples and houses. Burning incense, however, does contribute to increased PM2.5 pollution. The concentrations of PM2.5 in temple air reach levels between $75 \mu \mathrm{g} / \mathrm{m}^{3}$ and $700 \mu \mathrm{g} / \mathrm{m}^{3}$. Although incense is also burnt at other times, it is much more frequent during the Chinese New Year. On the first day of Chinese New Year in 2013, over 70,000 people visited Yonghe Lama Temple in Beijing to burn incense. This is just one example, and hundreds of temples exist in Beijing (Xiao, 2013). More than 400,000 people visited Guiyuan temple in Wuhan city to burn incense on the first day of Chinese New Year in 2012 (Xiong, 2011). Besides burning incense, "ghost money", a kind of imitation paper money, is also burned for good fortune and to appease the ancestors or wandering ghosts. Burning ghost money is a routine activity throughout the year in China. According to Chinese customs, people should burn ghost money for their ancestors regularly during the year, but this activity is much more prevalent during the Chinese New year, Chinese people believe that this will encourage their ancestors protect them. During Chinese New Year, especially New Year's Eve, the first day, the fifth day, and the fifteenth day of Chinese New Year, people burn more than 100,000 tons of ghost money in China (Tang, 2013). This produces huge amounts of ash, smog, and fire.

Exploding firecrackers, burning incense and ghost money releases a mass of $\mathrm{CO}, \mathrm{CO}_{2}, \mathrm{SO}_{2}, \mathrm{NO}_{2}$, and other harmful gases and particles, and leads to elevated fog and haze pollution during Chinese New Year. It is reported that PM2.5 is several times higher than the normal level in China during each Lunar New Year (Li, 2012). An air quality index (AQI) is an indicator commonly used by government agencies to tell the public how clean or polluted the air is. The index ranges from 0 to 500 . Higher AQI values represent higher levels of air pollution and greater health concerns. China's Ministry of Environmental Protection (MEP) has defined a general relationship between $\mathrm{AQI}$ and health implications. When the $\mathrm{AQI}$ is between 0 and 50 , the air quality is considered excellent and there are no health implications. The air quality is considered good when the AQI ranges from 51 to 100 , but a few hypersensitive individuals should reduce outdoor exercise. The air quality is lightly polluted and moderately polluted when the AQI ranges from 101 to 150 and 151 to 200 , respectively, and individuals with breathing or heart problems should reduce outdoor exercise. The air quality is heavily polluted when the AQI is between 201 and 300, even healthy people will be noticeably affected. The air quality is severely polluted when the AQI is higher than 300 and may lead to severe irritations and may trigger other illnesses. As shown in Fig. 1, the AQI of Beijing during Chinese Nian is higher than on any other days, especially on Chinese New Year's Eve, Chinese New Year Day, and on the day of or following the Chinese Lantern Festival. These three days are very important in Chinese culture. The hourly PM2.5 concentration at the America Embassy in Beijing also exhibits the 


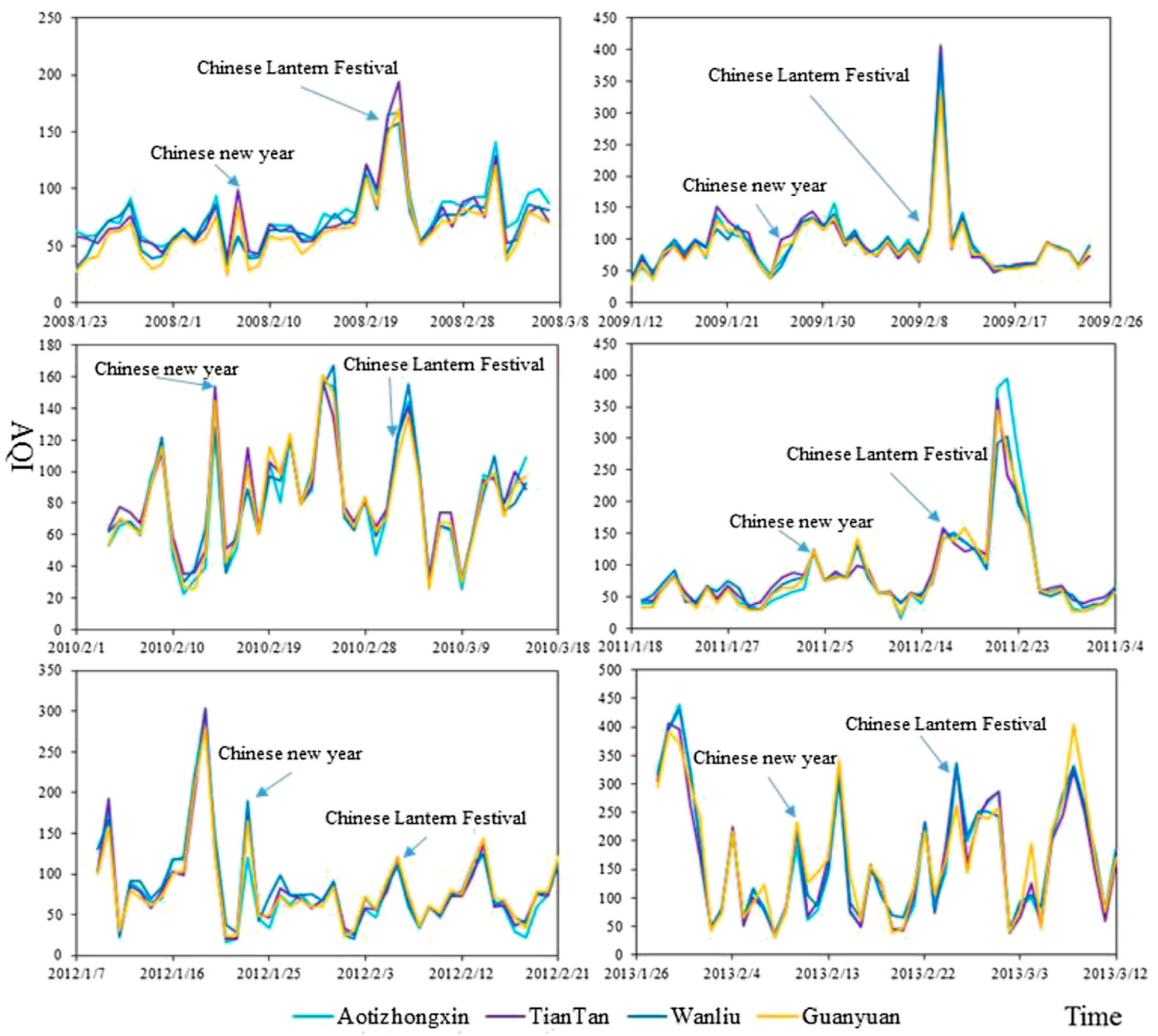

Fig. 1. Daily Air quality index (AQI) during Chinese Nian period at four stations in Beijing.

same trend from 2010 to 2013 (Fig. 2). As mentioned above, PM2.5 concentrations were as high as $1593 \mathrm{ug} / \mathrm{m}^{3}$ at one o'clock on the night of Chinese New Year's Eve at an air monitoring station in Beijing (Li, 2012). On the Chinese New Year's eve of 2013, PM2.5 concentrations increased from $81.4 \mathrm{ug} / \mathrm{m}^{3}$ at $8 \mathrm{PM}$ to $124.8 \mathrm{ug} / \mathrm{m}^{3}$ at $9 \mathrm{PM}, 135 \mathrm{ug} / \mathrm{m}^{3}$ at $10 \mathrm{PM}$, and $151.3 \mathrm{ug} / \mathrm{m}^{3}$ at $11 \mathrm{PM}$, to $523.7 \mathrm{ug} / \mathrm{m}^{3}$ at midnight of the first day of Chinese New year in Shanghai. And the welcoming of the God of Wealth on the fifth day of Chinese New Year caused another peak in air pollution in 2013 (Zhang, 2013).

\section{Initiatives and possible changes}

\subsection{Some changes in chinese cities}

As a long-established tradition, Chinese Nian is deeply embedded in Chinese society and would not be easily changed. However, it can probably be changed gradually. When unprecedented threats to health and safety, people will have to make an effort to change old rules and customs. The greatest barriers to a move towards more environmentally-friendly and sustainable behavior related to Nian are people's values and cultural customs. As a result of the serious air pollution triggered by celebrating the Chinese New year, both government and private groups have taken measures to reduce air pollution, which signifies that traditional culture is not unchangeable.
At the national level, the Chinese government initiated policies to limit the use of firecrackers as early as 2000, primarily due to human safety concerns. As air pollution in big cities was getting worse and worse in the years after 2010, governments paid attention to the impacts that lighting firecrackers had on air pollution. As obligatory regulations set by the Environment Ministry of China (EMC), PM2.5 was gradually incorporated into the urban environmental protection standards. According to the "Atmospheric Pollution Prevention Action Plan" issued by the State Council in September 2013, the number of cities who reported their air quality hourly online increased from 74 of 2013, to 161 of 2014, and to 338 of 2015 ( Wu, 2015). This turned into a grassroots movement to monitor air quality. The Chinese government also issued several policies regulating fireworks. The Hangzhou municipal government issued a notification to encourage a Spring-festival with no or fewer fireworks in January 2013. These types of actions will have longterm positive effects.

New measures have also been initiated at the local level to tackle air pollution. For example, Hangzhou municipal government's policy was widely supported by many Internet users. Some environmentalists even invented new ways to celebrate the New Year, such as trampling balloons instead of lighting firecrackers. The news on Hangzhou reported that the sales volume of fireworks and PM2.5 both decreased significantly during the same period at the Spring Festival in 2013, compared to 2012 (Zhao, 2013). In Wuhan 


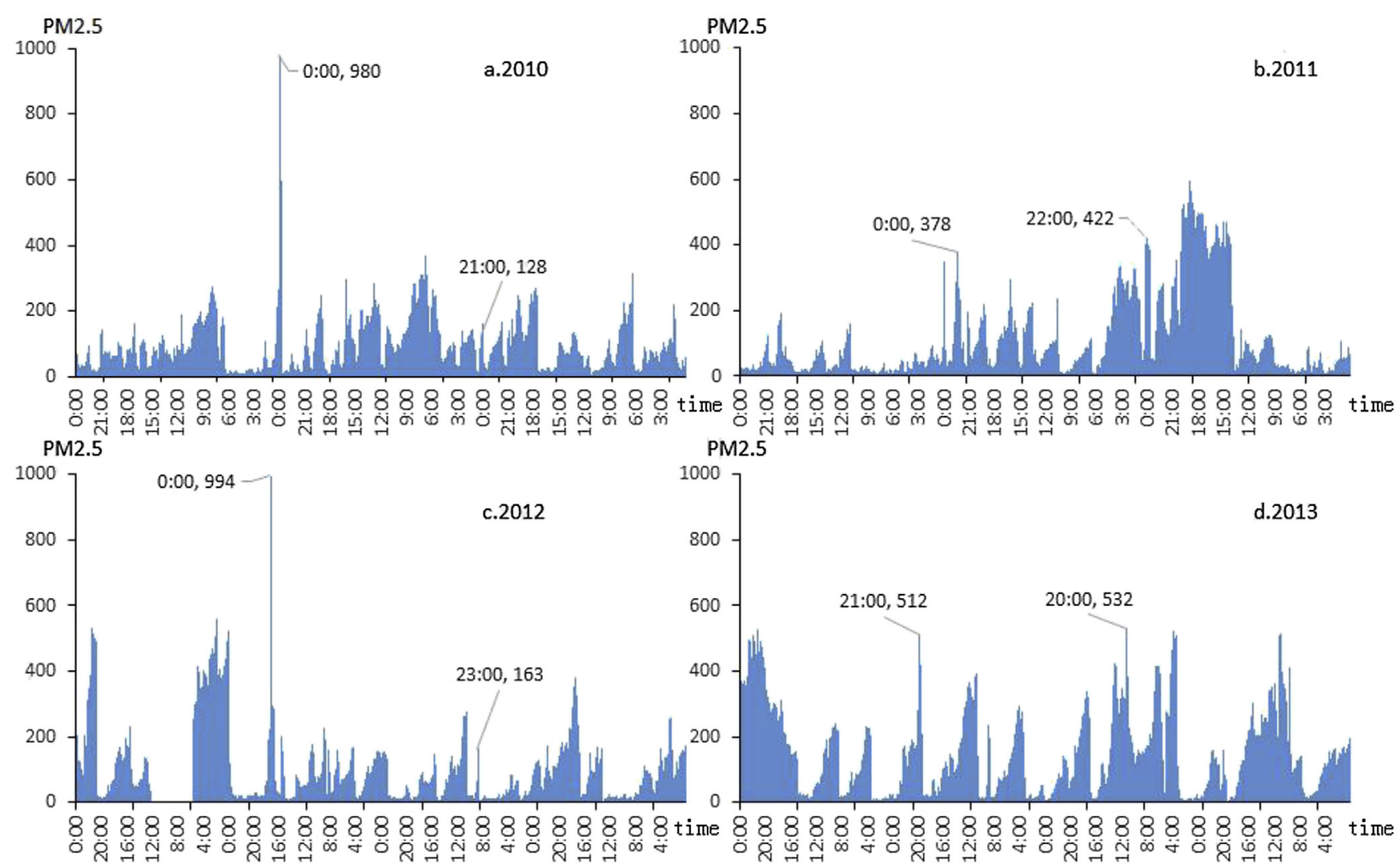

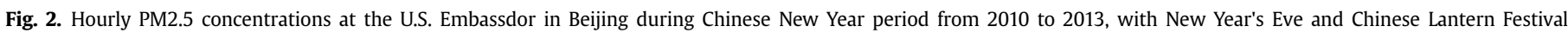
highlighted.

city, Guiyuan temple initiated new prayer methods using mobile phone messages and the Internet during Chinese New Year, this greatly reduced the lighting of incenses at the temple (Xiong, 2011). Medias including TV programs, newspapers, and mobile phone messages all encouraged people to have a low-pollution Nian, which had a significant positive impact on people's behavior during Chinese New Year. The hourly PM2.5 values released by the government increased awareness and contributed to reduced air pollution. For example, after the high PM2.5 values in temples were widely broadcasted, people began to understand the problem and became willing to adapt their behavior.

The lighting of fireworks was reduced in big cities like Beijing and Shanghai year by year, after 2010, which was not only enforced by regulations, but also by media persuasion and people's selfreflection. The practices of burning incenses and ghost money decreased as well. Nevertheless, these changes, although steps in the right direction, are not enough. More time and efforts will be required to transform the social and cultural traditions.

\subsection{Possible and necessary changes in the future}

Reducing air pollution caused by Chinese Nian culture is relatively simple, compared to air pollution as a whole. According to the framework illustrated by Bors and Solomon (2013), air pollution caused by Chinese Nian culture is a much less-nested environmental problem. The scientific explaining behind it is clear, and primarily involves atmospheric chemistry. The human factors and activities that are associated with the problem consist of the companies that produce fireworks and firecrackers, incenses, and "ghost money", the public, and governments. The necessary governance and management structures involve regulation, self- inspection, and advocacy of Medias and NGOs. Effective regulatory institutions should be designed to address this problem. The actors and their activities associated with air pollution during Chinese New Year should be encouraged to reduce PM2.5 release and build a low-emission society (Shi et al., 2014).

The problem of PM2.5 release during the Chinese New Year must be addressed in four primary ways. First, fireworks sources should be controlled and limited. Besides limiting the usage of fireworks by individuals, the Chinese government should also limit firecrackers and fireworks sales. During the Chinese New Year, a quota should be placed on the amounts of fireworks and firecrackers sold in the markets. As well, the companies that produce fireworks should be subsidized for sales losses. The Beijing government's policy states that fireworks and firecrackers should be removed from market shelves if there is an "orange signal warning" (which means more than three days with an air quality index between 300 and 500) during western New Year and Chinese New Year. Second, governments should issue laws to limit the lighting of fireworks and burning of incense and paper money in certain areas. Third, medias should inform the public regarding the impacts that the usage of fireworks, incense, and paper money have on human health, and encourage society to take measures to change the traditional ways of celebrating Chinese New year. Last but not least, bottom-up innovations regarding low-carbon, low-pollution means of celebrating the Chinese New Year should be encouraged, rewarded, and advocated.

Culture has a large impact on environment governance (Adger et al., 2012). Besides China, there are cities of other countries lighting fireworks during festival celebrations, which has an important effect on PM2.5 concentrations (Drewnick et al., 2006; Vecchi et al., 2008; Mlakar, 2012; Yerramsetti, 2013), but their 
cultural practices and social movements are different from China. For example, the US tradition involving fireworks to celebrate Independence Day began with a letter from John Adams to his wife (Davis, 2014). A few words written by the great man resulted in a holiday tradition that has continued for 200 years. Although cultural backgrounds and traditions are different for each country, the effects of air pollution are nearly the same.

The dilemma between traditional culture and environmental protection cannot be solved easily (Ye et al., 2014), mainly because the connections between social and cultural practices and environmental problems is multi-scalar and complex. On different spatial or administrative levels, cultural practices can lead to various environmental problems, and social movements differ accordingly (Escobar, 1998). As Jamison (2003) noted: "effective public engagement in environmental politics needs, of course, people who are willing to be involved, who, in one of its various forms, have an 'ecological consciousness'; but there are also a number of supportive conditions, or social innovations, that are even more important if that consciousness, so to speak, is be cultivated and contribute to cultural transformation".

Environmental governance also needs to address multi-stakeholder actions. Governments, pollution producers, civilians, and the media all have their responsibility in pollution control. Reducing air pollution during Chinese New Year needs to change not only through policy structure, but also individual's behaviors. The former is an up-down strategy, and the latter is a bottom-up strategy. If individuals realize the importance of PM2.5 reduction and work together, the problem of air pollution can be resolved, at least during the Chinese New Year.

\section{Conclusions}

The Chinese Nian culture is a significant and direct factor leading to air pollution in China. Unfortunately, few people recognize the role of culture in dealing with environmental problems. Although cultural changes do not take place over a short time, people can gradually change the traditions, as long as they fully realize the threats and risks that traditions or customs exert on the environment.

Laws and policies should be designed to improve the effectiveness of PM2.5 control. Governments, industry, and civil society should work together to navigate positive initiatives. Public education and media navigation are necessary in dealing with the cultural aspects of environment pollution. People should also be provided more green options to make up for the loss of traditional activities or customs. Practicing sustainable activities during Chinese New Year can help to reduce the production of air pollutants at their sources (Shi et al., 2014).

\section{Acknowledgment}

This work is supported jointly by the National Natural Science Foundation of China (Grant No. 41171133, 41001080 \& 41471135) and the National Social Science Foundation of China (Grant No. 09BSH024). It is also funded by the Priority Academic Program Development of Jiangsu Higher Education and Institutions Jiangsu Center for Collaborative Innovation in Geographical Information Resource Development and Application. The insightful and constructive comments from the editors and reviewers are appreciated.

\section{References}

Adger, W.N., Barnett, J., Brown, K., Marshall, N., O'Brien, K., 2012. Cultural dimensions of climate change impacts and adaptation. Nat. Clim. Change. 3, $112-117$.
Bors, E.K., Solomon, S., 2013. How a nested framework illuminates the challenges of comparative environmental analysis. Proc. Natl. Acad. Sci. 110, 7531-7532.

Cheng, Y., Engling, G., He, K.-b., Duan, F.-k., Du, Z.-y., Ma, Y.-l., Liang, L.-l., Lu, Z.-f. Liu, J.-m., Zheng, M., Weber, R.J., 2014. The characteristics of beijing aerosol during two distinct episodes: impacts of biomass burning and fireworks. Environ. Pollut. 185, 149-157.

Crang, M., 1998. Cultural Geography. Routledge, London.

Davis, C., 2014. Fireworks' 'recreational Pollution' Makes Environmentalists Fume. China Daily USA, 2014.6.26.

Drewnick, F., Hings, S.S., Curtius, J., Eerdekens, G., Williams, J., 2006. Measurement of fine particulate and gas-phase species during the new year's fireworks 2005 in mainz, Germany. Atmos. Environ. 40, 4316-4327.

Escobar, A., 1998. Whose knowledge, whose nature? Biodiversity, conservation, and the political ecology of social movements. J. politic Ecol. 5 (1), 53-82.

Gregory, D., Johnson, R., Pratt, G., Watts, M., Whatmore, S., 2009. The Dictionary of Human Geography, fifth ed. Blackwell, Oxford.

Hang, W., Chen, J., 2000. Effect on environmental quality of and control of setting straw on fire on field. Adm. Tech. Environ. Monit. 12, 36-37.

Huang, J., 2013. The Trash of Fireworks Decreased by Nearly One Thousand Ton during Spring Festival in Beijing in 2013. Beijing Youth Daily, 2013. 2.17.

Huang, X., Song, Y., Li, M., Li, J., Zhu, T., 2012. Harvest season, high polluted season in east China. Environ. Res. Lett. 7, 1-7.

Jamison, A., 2001. The Making of Green Knowledge: Environmental Politics and Cultural Transformation. Cambridge University Press.

Jamison, A., 2003. The making of green knowledge: the contribution from activism. Futures 35 (7), 703-716.

Jun, J., Ying, W., Lingjun, L., Jinxiang, L., Qiang, W., 2007. Particles pollution and impact caused by fireworks in beijing during Spring Festival. Environ. Pollut. Control 29, 229-232.

Li, Q., 2012. Send of Firecrackers Lead to PM2.5 Increased to 80 Times in Chinese New Year's Eve of 2012. Beijing Times, 2012.1.24.

Li, X., Guo, X., Liu, X., Liu, C., Zhang, S., Wang, Y., 2009. Distribution and sources of solvent extractable organic compounds in PM2.5 during 2007 chinese spring festival in Beijing. J. Environ. Sci. 21, 142-149.

Marshall, J., 2013. PM 2.5. Proc. Natl. Acad. Sci. 110 (22), 8756

Melamed, M.L., Zhu, T., Jalkanen, L., 2013. Urban Air Pollution: a New Look at an Old Problem, pp. 20-23.

Milton, K., 2013. Environmentalism and Cultural Theory: Exploring the Role of Anthropology in Environmental Discourse. Routledge.

Mitchell, D., 2000. Cultural Geography: a Critical Introduction. Blackwell, Oxford.

Mlakar, P., Božnar, M.Z., Grašič, B., Popović, D., 2012. Fireworks air pollution in Slovenia. Int. J. Environ. Pollut. 50, 31-40.

Rao, P., 2013. The Trash of Fireworks and Firecrackers Decrease by 20\% in the Night of Chinese New Year's Eve of 2013 Compare to the Same Period in 2012 in Beijing. The Beijing News, 2013.2.11.

Shi, H., Wang, Y., Huisingh, D., Wang, J., 2014. On moving towards an ecologically sound society: with special focus on preventing future smog crises in China and globally. J. Clean. Prod. 64, 9-12.

Shi, Y., Zhang, N., Gao, J., Li, X., Cai, Y., 2011. Effect of fireworks display on perchlorate in air aerosols during the Spring Festival. Atmos. Environ. 45, 1323-1327.

Tang, Z., 2013. The Environment Cost of Chinese New Year. Caijing Review, 2013.2.20.

van Donkelaar, A., Martin, R.V., Brauer, M., Kahn, R., Levy, R., Verduzco, C. Villeneuve, P.J., 2010. Global estimates of ambient fine particulate matter concentrations from satellite-based aerosol optical depth: development and application. Environ. health Perspect. 118, 847.

Vecchi, R., Bernardoni, V., Cricchio, D., D'Alessandro, A., Fermo, P., Lucarelli, F. Nava, S., Piazzalunga, A., Valli, G., 2008. The impact of fireworks on airborne particles. Atmos. Environ. 42, 1121-1132.

Wang, Q., 2013. China's citizens must act to save their environment. Nature 497, 159.

Wang, Y., Zhuang, G., Xu, C., An, Z., 2007. The air pollution caused by the burning of fireworks during the lantern festival in Beijing. Atmos. Environ. 41, $417-431$.

Williams, R., 1981. Culture. London: Fontana.

Wu, J., 2015. The Ministry of Environmental Protection of China: over 338 Cities Carry Out the New Standard of City Air Quality Monitoring (accessed 17.01.15.) http://news xinhuanet.com/energy/2015-01/17/c 127394957.htm.

Xiao, H., 2013. 70 thousand People Went to Yonghe lama Temple for the First Incense at the First Day of Chinese New Year. The Beijing News, 2013.2.11.

Xiong, J., 2011. Wuhan: the Concept of Environment Protection Was Accepted during Chinese New Year of 2011, Low Carbon Nian Is Becoming a Kind of Fashion, 2011.2.7.

Xu, J., Ding, G., Yan, P., Zhang, J.-C., Wang, S.-F., Zhang, Y.-M., Meng, Z.-Y., Liu, Y.-C., Zhang, X.-L., 2006. Effect of firecracker setting-off on the fine particle pollution in beijing downtown areas. J. Saf. Environ. 6, 79-82.

Ye, C., Chen, R., Young, C., 2014. Nian: when chinese mythology affects air pollution. Lancet $383,2125$.

Yerramsetti, V.S., Sharma, A.R., Navlur, N.G., Rapolu, V., Dhulipala, N.C., Sinha, P. 2013. The impact assessment of diwali fireworks emissions on the air quality of a tropical urban site, Hyderabad, India, during three consecutive years. Environ. Monit. Assess. 185, 7309-7325.

Yin, C., Zhu, B., Cao, Y., Su, J., Wang, X., Wang, H., 2011. The origin of crop residue burning impact on air quality of Nanjing. China Environ. Sci. 31, 207-213. 
Yu, X., Shi, C., Ma, J., Zhu, B., Li, M., Wang, J., Yang, S., Kang, N., 2013. Aerosol optical properties during firework, biomass burning and dust episodes in Beijing. Atmos. Environ. 81, 475-484.

Zhang, M., Wang, X., Chen, J., Cheng, T., Wang, T., Yang, X., Gong, Y., Geng, F., Chen, C., 2010. Physical characterization of aerosol particles during the chinese New Year's firework events. Atmos. Environ. 44, 5191-5198.

Zhang, Y., 2013. The Trash of Fireworks and Firecrackers Decreased Twenty Percent Compared to the Same Period in 2012 in Shanghai. International Finance News, 2013.2.18.
Zhao, Y., 2013. Fireworks Lead to PM2.5 Increase, Environmentalists Trample the Balloons to Enjoy Chinese New Year. China News, 2013.2.6.

Zhu, B., Su, J.-F., Han, Z.-W., Cong, Y., Wang, T.-J., Cai, Y., 2010. Analysis of a serious air pollution event resulting from crop residue burning over Nanjing and surrounding regions. In: SPIE Optical Engineering Applications. International Society for Optics and Photonics, 78090F-78090F-6. 